\title{
Effect of Education and Monitoring on Developing Foot Care of Elderly with Diabetes Mellitus
}

\author{
Saadet Can Cicek ${ }^{1}$, Feray Gokdogan ${ }^{2}$ \\ ${ }^{1}$ Bolu Abant Izzet Baysal University, Faculty of Health Sciences, Nursing Department, Internal Medicine Nursing, Bolu, Turkey. \\ ${ }^{2}$ Cyprus International University, Faculty of Health Sciences, Nursing Department, Nicosia/Turkish Republic of Northern Cyprus. \\ Correspondence Author: Saadet Can Cicek \\ E-mail: saadet.cancicek@ibu.edu.tr \\ Received: $23.10 .2020 \quad$ Accepted: 17.05 .2021
}

\begin{abstract}
Objective: To determine the effect of education and monitoring on developing foot care in elderly with diabetes.

Methods: This study was a controlled experimental research. The study was performed with 45 elderly with diabetes in the control group and 45 in the intervention group who met inclusion criteria for the study. The participants were registered in one center and in a public hospital between the dates of September 2012-September 2013. Training and follow-up on foot care were carried out for the intervention group by performing four-foot examinations in both groups.
\end{abstract}

Results: Diabetic foot information and foot care behavior scores showed significantly greater increases in the intervention group compared to controls. A significant difference in total foot examination score was determined between groups and in time $(p<0.05)$.

Conclusion: The results have shown that education and monitoring were effective in developing foot care in participants.

Keywords: Elderly, diabetes mellitus, foot care, monitoring, education, nursing

\section{INTRODUCTION}

Diabetes prevalence is growing worldwide and is becoming an epidemic and endemic problem with the social and economic burden. Its prevalence and its co-morbidities and mortality are higher in the elderly than in young people (1). Approximately one-quarter of people over the age of 65 years have diabetes, and this proportion is expected to increase rapidly in the coming decades (2). In 2019, the estimated number of people over 65 years of age with diabetes was 111 million. One in five adults in this age group is estimated to have diabetes. It is projected that by 2030 the number of people over 65 with diabetes will further increase to 195 million. By 2045, it will reach 276 million (1). Furthermore, nearly half of adults aged 65 years or older had prediabetes (3) Aging is considered a major risk factor for diabetes (4). Reasons like decreased independence in elderly with diabetes decreased self-care ability, and comorbidities affect diabetes management in a negative way (5).

With increasing age and duration of disease, both micro and macrovascular complications are more prevalent in the elderly. Together with complications, Peripheral Neuropathy (PN) and foot infections cause non-healing wounds in the elderly, increasing the risk of amputation in the lower extremities. More than $85 \%$ of amputations are preceded by an active foot ulcer. Diabetic foot represents the most common cause of hospitalization in patients with diabetes (6). Diabetic foot is one of the most serious and costly complications of diabetes. Lower limb amputation in people with diabetes is 10 to 20 times more common compared to those without diabetes. The 5-year relative mortality after diabetic foot ulcer is $48 \%$. This is clearly higher than most cancers (1). Peripheral Arterial Disease (PAD) is an independent risk factor for subsequent ulceration and limb loss in diabetes. Up to $15-25 \%$ of patients with diabetes will develop a foot ulcer sometime during their lives (7).

In addition to increasing neuropathy and vascular disease prevalence with age, it is difficult for the diabetic elderly to take foot and nail care as a result of arthritis, restriction of joint movements, walking abnormalities, lack of movement, dementia and decreased vision (6). Diabetic foot problems often emerge because of insufficient care and follow-up. It was reported in previous studies that half of the foot injuries are reported to be preventable with regular training and foot care. The easiest and cheapest way to prevent foot complications is to observe regularly, which is one of the most 
effective methods $(8,9)$. Elderly with diabetes are in a highrisk group in terms of diabetic foot management (1). The risk of developing diabetic foot must be identified by nurses by performing an examination of the person with diabetes and relevant training must be planned and followed-up according to the risk category (10). The visual ability and reach-the-feet must also be evaluated in the examination (6). In addition to these precautions, glycemic control is also extremely important in the prevention of diabetic foot $(1,11)$.

With the increase in the elderly population, foot ulcers increase parallel to diabetes prevalence. No studies were detected in the literature conducted in our country on the follow-up and training intervention by determining the risk of the diabetic foot to prevent foot problems in elderly with diabetes. It is important to consider the age factor in the training regarding foot care by evaluating foot risk in elderly diabetics and monitoring the sustainability of foot care and training. We believe that the present study, which was planned with a sampling of elderly with diabetes, is an original nursing study, and will contribute to scientific evidence in this field. Therefore, the aim of the study is to determine the effect of training and monitoring on developing foot care in elderly with diabetes.

\section{Hypothesis}

$\mathrm{H}_{1-1}$ : The training and follow-ups have effects on improving the foot examination scores of the elderly with diabetes".

$\mathrm{H}_{1-2}$ : The training and follow-up have an effect on increasing the foot care behavior of the elderly with diabetes".

$\mathrm{H}_{1-3}$ : The training and follow-up have an effect on increasing the knowledge of diabetic foot care of the elderly with diabetes.

\section{METHODS}

\subsection{Study design and setting}

This study was conducted as a controlled experimental type study. The universe of the study consisted of 85 elderly with diabetes registered in an elderly center and 680 elderly with diabetes who applied to a diabetes education unit of a public hospital between September 2012 and 2013. Since 16 elderly with diabetes did not comply with the inclusion criteria among the 85 elderly people who had diabetes in the intervention group of the study, 69 were included in the intervention group. As the same number of the elderly with diabetes in the intervention group would be recruited in the control group, it took approximately four months to reach 69 people out of the 680 elderly with diabetes who were recorded in the diabetes education unit of the hospital for their routine treatment and care. A total of 78 elderly people with diabetes applied to the unit in this 4-month period, and 69 people were included in the control group as 9 people with diabetes were not eligible. The study was terminated for 9 elderly with diabetes who met the study termination criteria in the intervention group and 10 in the control group during the follow-up period. When the follow-up of 60 people continued in the intervention group, the data of 45 elderly people with diabetes, whose follow-up was completed, were transferred into the computer, and power analysis was made. The sampling power was found to be $100 \%$ in $95 \%$ Confidence Interval with Power Analysis in the 45-people sampling by considering the Diabetic Foot Knowledge (SD:1) and Foot Care Behavior (SD: 11) Scale $(12,13)$. The sampling of the study consisted of 90 elderly people with diabetes. For this reason, as the sufficient sample size was reached, 15 elderly with diabetes from the intervention group and 14 from the control group were excluded from the follow-ups (Figure 1).

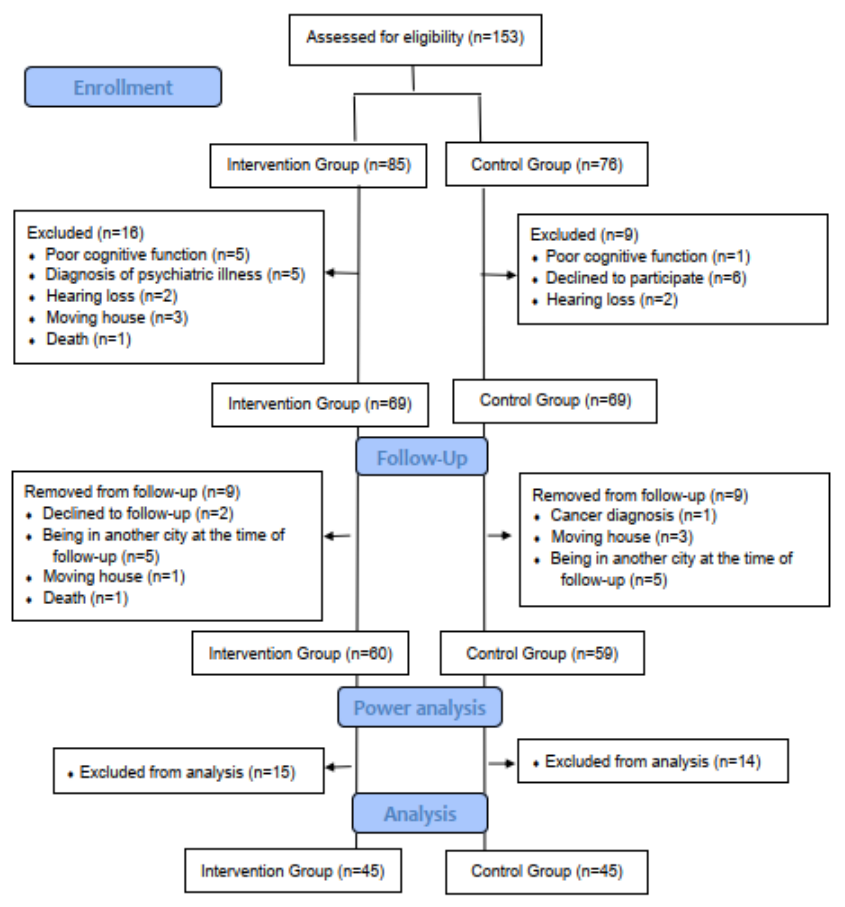

Figure 1. Flow Diagram

The inclusion criteria were as follows; having been diagnosed with Type 2 Diabetes, $\geq 65$ years of age, not having received diabetic foot care training, having no problems in communication, having good cognitive functions according to Mini Mental Test, having no diagnosis of psychiatric disease, and accepting to participate in the study. The exclusion criteria were as follows; the desire to leave the study, not attending at least one of the four follow-ups of the study, being out of the city during the follow-up process, being diagnosed with a serious illness that requires treatment, or passing away.

\subsection{Sampling and group allocation}

Those who were registered in the Elderly Center constituted the Intervention Group, those who applied to the Diabetes Education Unit constituted the control Group. The Elderly Center is a center where the elderly are monitored in their own environment, the health and social problems of the elderly are determined during working hours, and solution services for these problems are provided under the 
management of nurses. The center serves individuals who reside in the neighborhood to which it is attached. Home visits are made by nurses with three-month intervals at the latest in this center, although it is more frequent according to the needs of the elderly. As the number of the elderly with diabetes who were registered in the elderly center did not meet the sampling size determined according to power analysis, the intervention and control groups were taken from different centers. Because of the opportunity to be able to follow-up the elderly with diabetes registered in the center in their own environments, they were chosen as the intervention group. The elderly with diabetes admitting to the diabetes education unit of the hospital during the implementation period of the study constituted the control group. In this way, it was prevented that the intervention performed would affect the participants in the control group by taking the study groups in different centers.

\subsection{Description of the interventions}

\section{Intervention Group}

The diabetic foot risk group was determined by carrying out foot examination to the participants in this group, and foot care training and follow-up were performed. A total of four interviews were carried out in the initial, first, third and sixth months. In the first meeting, foot examination was carried out, and individual training was provided to the participants, and the training booklet was given by considering the age factor for diabetic foot care, which lasted 30-45 minutes. Education was performed by using mixed learning methods consisting of lecture, question-answer, demonstration, and practice. Education Booklet included information on: the healthy foot, diabetic foot complications, how diabetes affects your feet, frequently occurring foot problems, surveillance of early foot problems, how to check your feet and problems to look for, nail and skincare, how to choose a shoe and footwear, preventing foot injuries, regular check-up, compliance with diabetes treatment plan, blood glucose, blood pressure and blood lipids monitoring, daily physical movement and quitting smoking (14-19). The foot examination was repeated in the other three interviews, and incomplete information about foot care training was completed, and incorrect information was corrected. Diabetic Foot Knowledge Subscale (DFKS) and Foot Self-Care Behavior Scale (FSCBS) were applied in each interview.

\section{Control Group}

When routine follow-ups of the participants in this group were performed in a hospital, foot examination was performed and no interventions were carried out. Foot examination, DFKS and FSCBS application frequency were the same as in the Intervention Group. After the $4^{\text {th }}$ interview, recommendations were made for consultation by providing individual foot care training.

\subsection{Measurement instruments}

Diabetic foot care and training form, mini mental testing readjusted for the elderly in literate and illiterate individuals and uneducated, participant characteristics form, foot examination form, DFKS and FSCBS were used.

Diabetic foot care and training form: It was determined whether the participant had received previous individual training on diabetic foot care and applications at least for two hours by examining the foot by diabetic training nurse and following-up according to the pre-defined risk group $(8,9,20)$.

\section{The Revised Standardized Mini Mental Examination Test:} The test evaluates cognitive functions like orientation, record memory, attention and calculation, remembering and language (21). The validity and reliability study of the test was conducted for Turkey (22). Twenty-two points and below show possible cognitive disorders for literate people, and 18 points and below show possible cognitive disorders for illiterate people. The Cronbach Alpha value was 0.59 in the present study.

Participant characteristics form: The form was created by the researchers by scanning the literature. Form consists of five sections questioning socio-demographic characteristics (age, gender, education level, people they live with, etc.), habits (smoking, alcohol, and exercise), characteristics of the disease (diabetes diagnosis time, type of treatment, presence and type of complications, etc.), other chronic diseases and measurements (height, weight, body mass index, $\mathrm{HbA} 1 \mathrm{C}$ value, fasting-postprandial blood glucose and blood lipid levels) $(23,24)$. The data on chronic diseases other than diabetes were obtained by the researcher from file records and with face-to-face interviews, and were grouped according to International Disease Codes (25). Body Mass Index was evaluated as underweight (below 18.5), normal (18.5-24.9), slightly obese (25.0-29.9), obese (30.039.9), and excessively obese ( 40.0 and above) (26). Fasting and postprandial blood glucose measurements were taken with glucometer and capillary blood taken at each follow-up, $\mathrm{HbA1C}$ was recorded three times in total in 3-month average glucose levels, and blood lipid levels were recorded twice.

Diabetic foot evaluation form: The form was created by the researchers by scanning the literature. The physical examination of the foot in each follow-up is divided into six sections, and the scoring is made between 0 and 19. In physical examination, each problem (1) was scored, and the total score was scored between 0 and 19. $(27,28)$.

Presence of foot ulcer: During the examinations, the presence of ulcers was checked. If the patient had an ulcer, (1) point was given, if not (0) point was given.

Evaluation of structural anomalies of the feet and footwear: Deformities like hammertoe or claw toe, hydrocele, callus, fungi, hallux valgus, amputation and Charcot deformity were evaluated. If there were an anomaly in one of both feet, (1) point was given; if not (0) point was given. The width and foot bed, supporting the foot arch, and the suitability to the feet were evaluated, and each item was scored as (1) in there was compliance to each part, if not, $(0)$ point was given $(8,29)$. 
Peripheral neuropathy: The presence of any peripheral neuropathy was determined with PN symptoms in physical examination (complaints, place, time, etc.) and findings (sense of vibration, sharp-cunt perception, Achilies tendon reflex, sensory examination) scores (30). Even if there were no PN complaints or symptoms according to peripheral neuropathy symptom and finding score, in case there were PN findings $\geq 6$ points (moderate or severe), or in case there were moderate complaints and mild PN findings (3-5 points), it was evaluated as PN (31). If there was neuropathy (1) point was given; if not, (0) point was given.

Circulation: It was evaluated with intermittent limping, feet pulses and Ankle-Brachial Index (ABI) $(8,31,32)$. If there was intermittent-limping (1) point was given; if not, (0) point was given; if there was not any of the 4 pulses (1) point was given; if there was, (0) point was given; if $A B I$ was not normal in any of the right or left side, (1) point was given; if normal, (0) point was given.

Self-care knowledge on foot care: Answering "Yes" to any of the 6 questions in any follow-up was deemed to show a deficiency in self-care knowledge (29). If there was knowledge deficiency, (1) point was given; if not, (0) point was given.

Diabetic foot risk and management categories: It was evaluated according to the results of the examination of the feet (8). If the diabetic foot risk group was low (0) point was given; if high, (1) point was given.

Diabetic foot knowledge subscale: The scale consists of five items (33). The validity and reliability were conducted by Kır Biçer and Enç (34). Cronbach Alpha value was 0.67 in the initial measurement, 0.68 in the first month, 0.71 in the third month, and 0.70 in the sixth month.

Foot self-care behavior scale: The scale was developed by Borges and Ostwald (35) in 2008. The validity and reliability were conducted by Kır Biçer and Enç (36). Cronbach Alpha value was 0.79 in the initial measurement, 0.88 in the first month, 0.91 in the third month, and 0.92 in the sixth month.

\section{5. Data collection and procedure}

Data collection was performed by the researchers by face-toface interviews and physical examination. The diabetic foot risk group was determined by performing foot examination to the elderly with diabetes in the Intervention and Control Group. Although the frequency of follow-ups varied according to the risk group (8), a total of four interviews were conducted as the initial interview, and in the first, third and sixth months. The participants who could not come to the Elderly Center were visited at home.

\subsection{Ethical considerations}

The study was approved by the Ethical Committee of the hospital. Permission was obtained from the institutions in which the application was made. Before beginning the study, the researchers explained its purpose to those who fitted the inclusion criteria, and informed voluntary consent was obtained in writing from those who consented to participate.

\subsection{Statistical data analysis}

The analyses of the data were made in the Statistical Analysis System Institute, Cary, North Caroline-SAS 9.3 Package Program. The fitness of the points to normal distribution was checked with skewness and kurtosis; the homogeneity of the groups was evaluated with $\boldsymbol{t}$-test, Chi-Square or Fisher's Exact Test. Variance analysis was used in repeated measurements to compare the mean scores according to measurement times. In significant variables, the group or measurement time(s) that yielded the significance was determined with Duncan's Test. The level of significance was taken as $P<0.05$.

\section{RESULTS}

\subsection{Participant characteristics}

The mean age of the participants was $71.49 \pm 4.35$ in the intervention group, and $70.93 \pm 4.89$ in the control group. No significant differences $(P>.05)$ were detected between the two groups except in cigarette smoking, diabetes treatment types, and diabetes-related complications.

\subsection{Findings related to participants' diabetic foot information subscale (DFKS), foot self-care behavior subscale (FSCBS) and foot examination scores}

There was a significant difference in the mean DFKS points in the intervention and control group, and changed over time $(P<0.001)$. The change increased in every measurement from the initial follow-up in the intervention group compared to the control group (Table 1). This result confirmed the hypothesis that "training and follow-up have an effect on increasing the knowledge of diabetic foot care of the elderly with diabetes".

Table 1. Comparison of mean scores of the diabetic elderly in intervention and control group in terms of diabetic foot knowledge and foot care behavior during follow-up process

\begin{tabular}{lllll} 
Measures & DFKS & \multicolumn{3}{l}{ FSCBS } \\
& $\bar{x}_{ \pm S D}$ & & $\bar{x}_{ \pm S D}$ & \\
\hline & $\begin{array}{l}\text { Intervention } \\
(\mathrm{n}=45)\end{array}$ & $\begin{array}{l}\text { Control } \\
(\mathrm{n}=45)\end{array}$ & $\begin{array}{l}\text { Intervention } \\
(\mathrm{n}=45)\end{array}$ & Control $(\mathrm{n}=45)$ \\
\hline $\mathbf{1}$ & $2.51 \pm 1.27$ & $1.56 \pm 1.34$ & $48.69 \pm 9.98$ & $45.18 \pm 11.24$ \\
$\mathbf{2}$ & $3.18 \pm 1.08$ & $1.82 \pm 1.27$ & $61.13 \pm 7.21$ & $46.53 \pm 11.51$ \\
$\mathbf{3}$ & $4.16 \pm 0.85$ & $2.40 \pm 1.56$ & $66.82 \pm 4.95$ & $48.93 \pm 11.18$ \\
$\mathbf{4}$ & $4.73 \pm 0.50$ & $2.60 \pm 1.14$ & $70.64 \pm 3.16$ & $50.78 \pm 10.76$ \\
\hline Test & $p$ & & $p$ & \\
Time & $<0.001$ & & $<0.001$ & \\
Group & $<0.001$ & & $<0.001$ & \\
Time $x$ & & & & \\
Group & $\mathbf{0 . 0 0 6}$ & & $<0.001$ & \\
\hline
\end{tabular}

DFKS: Diabetic Foot Knowledge Subscale, FSCBS: Foot Self-Care Behavior Scale, SD: Standard Deviation 
There was a difference in terms of the mean FSCBS scores between the intervention and control group, and changed over time $(P<0.001)$ (Table 1$)$. This result confirmed the hypothesis that "training and follow-up have an effect on increasing the foot care behavior of the elderly with diabetes".

The mean foot examination points were compared according to the measurement times in the Intervention and Control Group (Table 2). Although there was a difference in terms of the structural abnormalities of the foot, neuropathy, lack of self-care knowledge, and diabetic foot risk score $(P<0.05)$; there were no differences in terms of footwear, neuropathy, and circulation score $(P>0.05)$. The lack of self-care knowledge score decreased more between the $1^{\text {st }}-2^{\text {nd }}$ measurements and the $3^{\text {rd }}-4^{\text {th }}$ measurements in the Intervention Group compared to the Control Group. The total score of foot examination was similar $(P=0.005)$, changed over time $(P=0.001)$, and the change was similar $(P>0.05)$. In the mean foot examination points; there was a significant difference between the $1^{\text {st }}-2^{\text {nd }}$ and the $3^{\text {rd }}-4^{\text {th }}$ measurements in both groups after the first measurement, more pronounced in the Intervention Group, and it was determined that there was an increase in the Intervention Group in the $4^{\text {th }}$ measurement, less pronounced in the Intervention Group. These results confirmed the hypothesis that "The training and follow-ups have effects on improving the foot examination scores of the elderly with diabetes".

\subsection{Findings related to physiological measurements}

The differences between mean systolic blood pressure, FBG and PBG between groups and the change over time were not significant $(P>0.05)$. In the mean diastolic blood pressure, the difference between groups was significant $(P=0.005)$, and there was no significant difference in change over time $(P>0.05)$. The diastolic blood pressure was low in the Intervention Group compared to the Control Group (Table $3)$. The difference between groups and the change over time in the mean $\mathrm{HbA} 1 \mathrm{c}$ score was not significant $(P>0.05)$ Table 4). The difference between the groups in the first interview and $4^{\text {th }}$ follow-up for mean triglyceride, cholesterol and LDL values and the change over time was not significant $(P>0.05)$. The mean HDL was found to be lower in two follow-ups in the Intervention Group compared to the Control Group, and the difference was found to be significant in the $4^{\text {th }}$ follow-up $(P=0.05)$ (Table 5).

Table 2. Comparison of mean scores of the diabetic elderly in intervention and control group in terms of foot examination during follow-up process

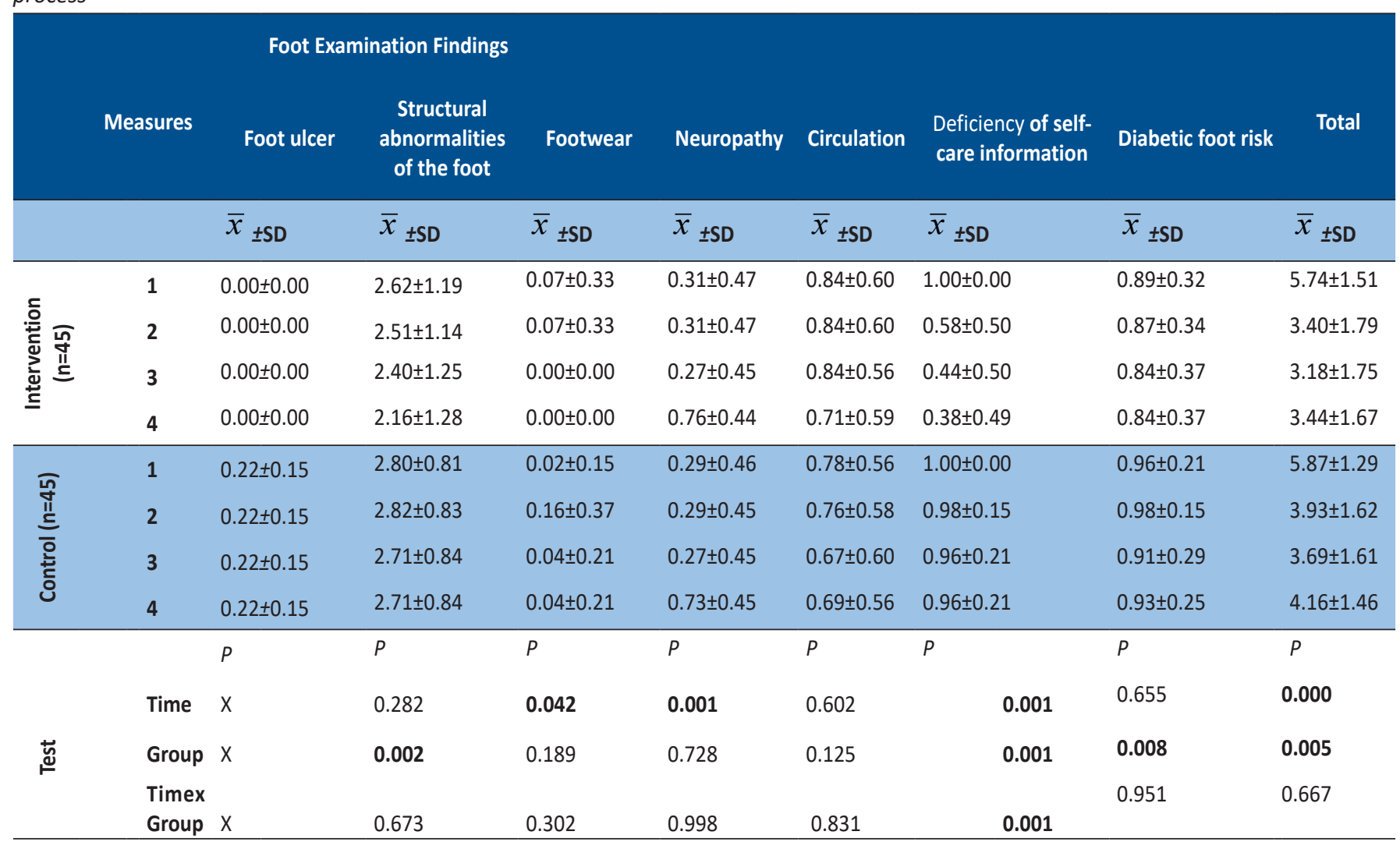

SD: Standard Deviation, $X$ : Since there were no foot ulcers in the Intervention Group during follow-up period, the change could not be compared in terms of foot ulcer according to intra and intergroup time. 
Table 3. Comparison of mean scores of the diabetic elderly in intervention and control group in terms of systolic blood pressure, diastolic blood pressure, $F B G$, and $P B G$ during follow-up process

\begin{tabular}{|c|c|c|c|c|c|}
\hline & Measures & Systolic Blood Pressure & $\begin{array}{l}\text { Diastolic Blood } \\
\text { Pressure }\end{array}$ & FBG & PBG \\
\hline & & $\bar{x}_{ \pm S D}$ & $\bar{x}_{ \pm \mathrm{SD}}$ & $\bar{x}_{ \pm S D}$ & $\bar{x}_{ \pm \mathrm{SD}}$ \\
\hline \multirow{4}{*}{ 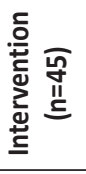 } & 1 & $130.44 \pm 13.81$ & $75.78 \pm 12.34$ & $136.56 \pm 38.87$ & $186.58 \pm 71.18$ \\
\hline & 2 & $128.89 \pm 14.50$ & $77.56 \pm 8.83$ & $140.12 \pm 55.95$ & $191.911 \pm 91.83$ \\
\hline & 3 & $126.00 \pm 13.21$ & $78.22 \pm 8.87$ & $124.09 \pm 22.27$ & $156.07 \pm 42.01$ \\
\hline & 4 & $129.11 \pm 13.28$ & $78.22 \pm 9.36$ & $127.11 \pm 31.10$ & $164.31 \pm 53.33$ \\
\hline \multirow{4}{*}{ 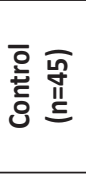 } & 1 & $128.33 \pm 13.48$ & $79.56 \pm 6.01$ & $133.62 \pm 42.86$ & $182.31 \pm 72.06$ \\
\hline & 2 & $128.22 \pm 11.34$ & $79.78 \pm 6.90$ & $138.47 \pm 65.58$ & $173.98 \pm 79.07$ \\
\hline & 3 & $126.89 \pm 13.11$ & $79.78 \pm 3.98$ & $137.22 \pm 72.63$ & $177.96 \pm 91.97$ \\
\hline & 4 & $129.78 \pm 13.40$ & $80.44 \pm 7.06$ & $144.21 \pm 57.05$ & $182.82 \pm 77.90$ \\
\hline \multirow{4}{*}{ 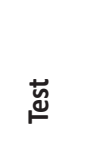 } & & $p$ & $p$ & $p$ & $p$ \\
\hline & Time & 0.392 & 0.562 & 0.729 & 0.34 \\
\hline & Group & 0.828 & 0.005 & 0.236 & 0.565 \\
\hline & Time $x$ Group & 0.865 & 0.830 & 0.442 & 0.224 \\
\hline
\end{tabular}

FBG: Fasting blood glucose PBG: Postprandial blood glucose, SD: Standard Deviation

Table 4. Comparison of mean scores of the diabetic elderly in intervention and control group in terms of hba1c during follow-up process

\begin{tabular}{lll} 
& & HbA1c \\
& Measures & $\bar{x} \pm$ SD \\
\hline \multirow{3}{*}{ Intervention $(\mathbf{n}=45)$} & $\mathbf{2}$ & $7.29 \pm 1.16$ \\
& $\mathbf{3}$ & $7.05 \pm 1.23$ \\
\hline \multirow{3}{*}{ Control $(\mathbf{n}=45)$} & $\mathbf{2}$ & $7.50 \pm 1.50$ \\
\hline$p$ & 3 & $6.96 \pm 1.67$ \\
\hline \multirow{2}{*}{ Test } & & $6.82 \pm 1.70$ \\
& Time & $6.96 \pm 1.67$ \\
\hline & Group & 0.592 \\
\hline & Time $x$ Group & 0.094 \\
\hline
\end{tabular}

SD: Standard Deviation,

Table 5. Comparison of Mean scores of the diabetic elderly in intervention and control group in terms of triglyceride, cholesterol, $H D L$ and $L D L$ in initial interview and fourth follow-up

\begin{tabular}{lccccc} 
Measures & $\mathbf{n}$ & Blood Lipids & $\begin{array}{c}\text { Intervention } \\
\text { Group }\end{array}$ & $\begin{array}{c}\text { Control } \\
\text { Group }\end{array}$ & $\boldsymbol{p}$ \\
& & & $\bar{x} \pm$ SD & $\bar{x} \pm$ SD & \\
\hline $\begin{array}{lcccc}\text { Initial } \\
\text { interview }\end{array}$ & 22 & Triglyceride & $163 \pm 63$ & $129 \pm 44$ & 0.245 \\
& 22 & Cholesterol & $202 \pm 32$ & $177 \pm 40$ & 0.251 \\
& 22 & HDL & $44 \pm 10$ & $51 \pm 16$ & 0.523 \\
& 22 & LDL & $123 \pm 31$ & $203 \pm 30$ & 0.279 \\
\hline Fourth & 44 & Triglyceride & $168 \pm 63$ & $144 \pm 66$ & 0.098 \\
interview & & & & & \\
& 44 & Cholesterol & $193 \pm 29$ & $189 \pm 38$ & 0.117 \\
& 44 & HDL & $42 \pm 11$ & $54 \pm 51$ & 0.051 \\
\hline & 44 & LDL & $122 \pm 30$ & $109 \pm 32$ & 0.122 \\
\hline
\end{tabular}

\section{DISCUSSION}

\subsection{Discussion of Findings Related to Participants' Diabetic Foot Information Scores}

It is important to evaluate problems that might occur after diagnosis, to provide training and regular follow-up and preventive behaviors to prevent diabetic foot development (37). It was reported that $50-85 \%$ of amputations can be prevented with early diagnosis, regular follow-up, and training (38).

The significant increase in the mean DFKS score in the Intervention Group compared to the Control Group was at the highest between the second and third measurements, and the least between the third and fourth measurements. In previous studies, it was reported that individuals with diabetes were inadequate in terms of their knowledge on foot care, and had low behavioral scores and poor attitudes (39-42). Guided by Bandura's Social Cognitive Theory, the foot self-care application increased in the $6^{\text {th }}$ week and the following three months after the foot self-care training applied to Type 2 diabetes individuals with low risk of foot ulcers (37). In the present study, which examined the effect of training in developing foot care knowledge and self-care practices, it was determined that there was a significant increase in the knowledge and self-care practices of the Intervention Group in one and a half and third months (43). In a study that examined the effect of foot care training, it was revealed that there was a significant difference between pre-test and post-test foot care knowledge score and patient foot examination and footwear use (44). In another study, individuals with diabetes were given foot care training in a four-week period, were followed up for six months, and the foot care knowledge increased in the Intervention Group in the first month and continued during the follow-up. 
There were no significant differences in foot lesions during the follow-up period (45). Similarly, in a study which trained patients 9 times about foot care and overall diabetes care, it was found that there was a significant increase in the knowledge in the application group (46). In the study conducted by Kır Biçer and Enç, the mean foot care knowledge score in the 6-month follow-up process of individuals with diabetes in the planned training program continued to increase as of the beginning in the experimental group, there was no change in the Control Group, and there was a significant difference between the follow-up according to the groups (34).

According to the results of the study, which reported a significant increase in foot care knowledge of individuals with diabetes after six weeks of foot care training (38) and after six months (47). On the contrary, in another study, it was reported that foot self-care knowledge did not increase in 6 months after application. The researchers emphasized that this difference was due to the small number of sampling (48).

In two studies $(49,50)$, it was shown that being able to obtain the knowledge would last for a longer period like 1-7 years. In our study, on the other hand, the increase in the mean diabetic foot knowledge score was at the highest level between the second and third measurements, and between the third and fourth measurements at the lowest level; and in line with these results, it is possible to speculate that the intervention was effective in increasing foot care knowledge in the first three months. This is because it is considered that the elderly with diabetes must be examined for foot examination every time they arrive for follow-ups to monitor changes, and foot care training would be provided according to the foot examination findings. No studies were detected in the literature in which foot care training and foot examination studies were conducted in each follow-up $(37,43,46)$; and it was determined that foot care training was not repeated in every follow-up, and that foot care knowledge was evaluated during the initial training process $(43,45,47)$.

\subsection{Discussion of Findings Related to Participants' Foot Care Behavior Scores}

It was reported in previous studies that self-care behaviors can be provided by increasing diabetes knowledge (51). In our study, the foot care behavior score increased at significant levels more in the Intervention Group. Effective management and control of diabetes require behavioral compliance. Studies showed that training practices increase the level of knowledge, positively affect the level of belief, and provide positive health behaviors $(52,53)$, three weeks after the training (24), and six months after the training (54) and foot self-care behaviors developed. The results of our study were found to be similar to studies supporting the effect of self-care practices in improving the performance of foot care behaviors $(38,47,48)$.

In our study, compared to the Control Group, the increase in the mean FSCBS scores was at the highest level between the $1^{\text {st }}-2^{\text {nd }}$ and $3^{\text {rd }}-4^{\text {th }}$ measurements, and the intervention was effective in acquiring foot care behavior as soon as in the first month. This might be because of the foot examination in each follow-up and the training given according to the examination findings. DFKS and FSCBS scores increased in the Intervention Group as well as in the Control Group, more pronounced in the Intervention Group. This increase may stem from the fact that participants in the Control Group regularly applied to the hospital with their own wishes for treatment and care of their diseases. In addition, it is considered that the follow-up process creates awareness and curiosity providing the opportunity to learn from experts on foot problems they experience in the elderly with diabetes in the Control Group.

\subsection{Discussion of Findings Related to Participants' Foot Examination Findings and Diabetic Foot Self-care Lack of Knowledge}

In the present study, the mean foot examination scores of the elderly with diabetes and the lack of self-care knowledge about foot care decreased in time in both groups. In the Intervention Group, the decrease in self-care knowledge scores between the $1^{\text {st }}-2^{\text {nd }}$, and $3^{\text {rd }}-4^{\text {th }}$ measurements greater than in the Control Group. In the literature, it was shown that training that focuses on foot self-care in patients in the long term improved self-care and foot care implementations, reducing lower-extremity amputation and foot ulceration in those who were at high risk for foot ulceration $(37,56)$.

There was a significant difference between structural abnormalities of the foot and the diabetic foot risk in the Intervention and Control Group in terms of mean scores. This difference may be the result of the variable nature of the scores of structural abnormalities of the foot, which can vary by increasing the knowledge and behavior scores of the participants with foot care training and follow-ups. Pieber et al. (57) conducted a study in which they provided training on diabetes and foot care for four weeks, followed up their patients, and compared the results with initial scores, the determined significant decreases in callus formation and inadequate nail care. Positive improvements were detected in foot care in the study, which compared foot examinations before the training, and after three and six months of the training (54). Routine foot care was provided to individuals with foot ulcers, and the risk of recurring foot ulcers decreased in one year (38). In two studies with a follow-up period of 6 months (32) and 18 months (46), no difference was detected between the groups in terms of foot lesions. It was reported that this might be due to the differences in foot examination findings of the participants involved in the sampling.

The difference between the Intervention and Control Group in terms of footwear, neuropathy and circulation scores was not significant. No studies were found in the literature in which diabetics were followed up according to risk groups by performing foot examination and foot care training as in our study. However, it was determined that there were studies in which it was reported that massage $(58,59)$, and exercise 
(60) were effective together with foot care examination in individuals with diabetes.

Asignificant difference was detected between the Intervention and Control Group in terms of the foot examination total scores, and it was determined that there was a decrease in the first measurement in both groups, more pronounced in the Intervention Group, and there was a decrease in the fourth measurement, less in the Intervention Group. The fact that there were decreases in foot examination score after the first measurement was associated with the follow-up period being 1 month between the first 2 measurements, and the increase in the $4^{\text {th }}$ measurement was associated with the period between the last two follow-ups being 3 months resulting in remembering the instructions given in the training.

It was determined in studies that there were positive improvements in foot care in the $3^{\text {rd }}$ and $6^{\text {th }}$ months after the training intervention (54), and there were significant decreases in callus formation and inadequate nail care at the end of the 6-month follow-up (57). In our study, the total score of foot examination consisted of factors that might vary with foot care training, follow-up, increased foot care knowledge, and behavior scores. The fact that there was a decrease in foot examination total score in the Intervention Group compared to the Control Group was considered as the results of training and follow-up on foot care in our study. The reason why there were decreases in the foot examination scores of the elderly with diabetes in the Control Group was the awareness that was raised when questions were asked about foot care knowledge and behavior to carry out fourfoot examinations.

\subsection{Discussion of findings related to participants' physiological measurement}

In our study, there were no significant differences in the inter - and intragroup comparison in terms of the mean scores of systolic blood pressure, FBG, PBG and HbA1c, but the difference between the groups in terms of the mean diastolic blood pressure scores was significant. The mean diastolic blood pressure was lower in the Intervention Group. This result is considered to be because of the evaluation of blood circulation when foot examinations were made, and the explanation of the results in blood pressure scores that were different from the normal values to diabetic participants, as well as directing them to the specialist physician for evaluation. The mean HDL scores in the Intervention Group were lower in both the beginning and in the 6-month than in the Control Group, and the difference was significant in the $6^{\text {th }}$ month. The reason for this significant difference in the Control Group might be considered as taking into account the warnings for regular referral to the Diabetes Training Unit, and the warnings made in terms of protecting and improving health. In a previous study, no significant relations were found between metabolic control variables and foot care training (54), and in another study, it was found that there was a significant decrease in HBA1c in the final test of the experimental group (35). It is speculated that increased compliance to self-care behaviors, diabetes knowledge, and treatment can be achieved with glycemic control (51). In the present study, the importance of blood sugar, blood pressure, and blood fat checks was emphasized in terms of foot health in the training given to the Intervention Group. It also found that there was a significant difference between the Intervention and Control Group in metabolic control variables other than Diastolic Blood Pressure and HDL value. The reason for this might be considered as that the majority of the elderly with diabetes in the Intervention Group do not go to the hospital regularly for treatment and care and because their metabolic control variables are not at the desired levels.

\section{CONCLUSION}

The results showed that training and follow-up are effective in increasing the knowledge on foot care, behavior and foot examination scores of the elderly with diabetes. In this respect, the following are recommended; identifying the risk of developing diabetic foot by examining the diabetic elderly by nurses, monitoring and scientifically evaluating the changes in foot care knowledge and behavior with individual foot care training and follow-up according to risk groups, including caregivers of diabetic elderly in training, re-conducting the study to increase the level of evidence, determining the effects of different interventions like exercise and reflexology in addition to training and follow-up interventions, creating evidence-based guidelines, and in this way, minimizing the complications of the foot due to diabetes.

\section{Limitations of the Study}

Among the limitations of the study are the small sampling size and six-month short-term training and follow-up period. In addition, one-on-one training is effective but timeconsuming, thus making it difficult to conduct daily in crowded clinics. To overcome this drawback, the effectiveness of foot care training could be evaluated by conducting training on larger groups.

\section{REFERENCES}

[1] International Diabetes Federation (IDF) Diabetes Atlas. Ninth edition. 2019. Available from: https://www.diabetesatlas. org/upload/resources/2019/IDF_Atlas_9th_Edition_2019.pdf Cited: 18.08.2019.

[2] American Diabetes Association (ADA). 12. Older Adults: Standards of medical care in diabetes-2019. The Journal of Clinical and Applied Research and Education. Diab Care 2019; 42(Suppl 1):139-147.

[3] Centers for Disease Control and Prevention (CDC). National Diabetes Statistics Report 2020 Estimates of Diabetes and Ilts Burden in the United States. Available from: https://www. cdc.gov/diabetes/pdfs/data/statistics/national-diabetesstatistics-report.pdf (Cited: 05.0.2019). 
[4] Bigelow A, Freeland B. Type 2 Diabetes Care in the Elderly. JNP 2017;13(3):181-186.

[5] Milanesi A, Weinreb JE. Diabetes in the Elderly 2017. Available from: https://www.ncbi.nlm.nih.gov/books/NBK279147/ Cited:05.08.2020.

[6] Munshi MD. Treatment of type diabetes mellitus in the elderly patient. Available from: https://www.uptodate.com/contents/ treatment-of-type-2-diabetes-mellitus-in-the-older-patient Cited:05.08.2020.

[7] Mariam TG, Alemayehu A, Tesfaye E, Mequannt W, Temesgen $\mathrm{K}$, Yetwale F, Limenih MA. Prevalence of Diabetic Foot Ulcer and Associated Factors among Adult Diabetic Patients Who Attend the Diabetic Follow-Up Clinic at the University of Gondar Referral Hospital, North West Ethiopia, 2016: InstitutionalBased Cross-Sectional Study, J Diabetes Res 2017;1-8.

[8] Etnyre A, Zarate-Abbott P, Roehrick L, Farmer S. The role of certified foot and nail care nurses in the prevention of lower extremity amputation. J Wound Ostomy Continence Nurs 2011;38:242-251.

[9] Fujiwara $Y$, Kishida K, Terao $M$, Takahara $M$, Matsuhisa $M$, Funahashi T, Shimomura L, Shimizu Y. Beneficial effects of foot care nursing for people with diabetes mellitus: An Uncontrolled before and after intervention study, J Adv Nurs 2011;67:1952-1962.

[10] International Working Group On The Diabetic Foot/IWGDF. Guidance on the Prevention of Foot Ulcers in At Risk Patients With Diabetes 2015:1-21.

[11] Lim JZM, Lynn NS, Thomas C. Prevention and treatment of diabetic foot ulcers. Journal of the JRSM 2017;110(3):104-109.

[12] Machin D, Campbell M, Fayers P, Pino A. Sample Size Tables for Clinical Studies, 2nd Edition. 1997; Blackwell Science. Malden, MA.

[13] Zar, Jerrold, H. Biostatistical Analysis (Second Edition). Prentice-Hall. 1984; Englewood Cliffs, New Jersey.

[14] A Guide for People With Diabetes, Take Care of Your Feet for a Lifetime, Control Your Diabetes for Life, U.S. Department of Health and Human Services Public Health Servise National Institues of Health, Nih Publication No.01-4285, 2003.

[15] Diabetic Foot Care: You and Your Feet, North Shore, Sea to Sky, Sunshine Coast, Powell River, Richmond and Vancouver, Providense Health Care, Catalogue No. FL.955.D54, 2010.

[16] Prevent Diabetes Problems Keep Your Feet and Skin Healthy, National Institues of Health, NIH Publication 2008; 5(7): 4282.

[17] Turkish Society of Endocrinology and Metabolism Diabetes Mellitus Study and Education Group Patient Education Booklets Series - 12, 2011. (Turkish).

[18] Yüksel A. Foot Care in Diabetes. Diabetes Nursing Basic Information, Erdoğan S (ed), Istanbul, Diabetes Nursing Association, 2002; s.127-140. (Turkish).

[19] X-Plain Diabetes-Footcare, The Patient Education Institute, Inc 1995-2005.

[20] Diabetes Foot: Risk Assesment Education Program Partipant's Package, Diabetes Nursing Interest Group, Registered Nurses Association of Ontario 2004:1-22.

[21] Folstein MF, Folstein SE, McHugh PR. "Mini MentalState" A Practical method for grading the cognitive state of patients for the clinician. J Psychiatric Res 1975;12(3):189-198.

[22] Keskinoglu P, Ucku R, Yener G, et al. Reliability and validity of revised Turkish version of Mini Mental State Examination (rMMSE-T) in community dwelling educated and uneducated elderly. Int J Geriatr Psychiatry 2009;24(11):1242-1250.
[23] Eason SL, Petersen NJ, Suarez-Almazor M, Favis B, Collins TC. Diabetes mellitus, smoking, and the risk for asymptomatic peripheral arterial disease: Whom should we screen? The Journal of the American Board of Family Practice 2005; 18: 355-361.

[24] Marso SP, Hiatt WR. Peripheral Arterial Disease in Patients With Diabetes, Journal of the American College of Cardiology 2006; 47: 921-929.

[25] World Health Organization http://www.who.int/ classifications/icd/en/ (11.10.2012).

[26] World Health Organization, Obesity: preventing and managing the global epidemic. Report of a WHO consultation. World Health Organ Tech Rep Ser. 2000, 894: 1-253.

[27] Frykberg RG. Diabetic foot ulcers: Pathogenesis and management. American Family Physician 2002; 66:1655-1662.

[28] Diabetes Foot: Risk Assesment Education Program Partipant's Package, Diabetes Nursing Interest Group, Registered Nurses Association of Ontario 2004:1-22.

[29] Diabetes Nursing Interest Group (DNIG). Registered nurses association of Ontario. Diabetes foot: Risk assesment education program partipant's package, 1-22. Available from: https://rnao.ca/sites/rnao-ca/files/Diabetes_Foot__ _ Risk_ Assessment_Education_Program_Full.pdf (Cited: 12.07.2019).

[30] Forouzandeh F, Aziz Ahari A, Abolhasani F, Larijani B. Comparison of different screening tests for detecting diabetic foot neuropathy. Acta Neurol Scand 2005;112(6):409-13.

[31] McCulloch DK, Nathan DM, Editor Mulder JE. Evaluation of the diabetic foot 2020. Retrieved from http://www.uptodate. com/contents/evaluation-of-the-diabetic-foot/contributors. (Cited: 08.07.2019).

[32] Asongwed Elmira T, ChesbroS teven B, Karavatas GCS. Peripheral arteial diseases and the ankle-brachial index: What home healthcare clinicians need to know, home healthcare Nurse 2009 27(3):160-167.

[33] Garcia AA, Villagomez ET, Brown SA, Kouzekanani K, Hanis CL. The Starr County Diabetes education study: Development of the spanish-language diabetes knowledge questionnaire. Diab Care 2001;24(1):16-21.

[34] Kır Bicer E, Enc N. Evaluation of foot care and self efficacy in patients with diabetes in Turkey an interventional study. Int Diabetes Dev Ctries 2016;36(3):334-344.

[35] Borges WJ, Ostwald SK. Improving foot self-care behaviors with pies sanos, West J Nurs Res. 2008;30(3):325-341.

[36] Kır Bicer E, Enc N. Validity and Reliability of the Turkish Adaptation of the Foot Self Care Behavior Scale. Journal of Nursing Forum in Diabetes, Obesity and Hypertension 2014;6(2):35-39. Available from: http://www.tdhd.org/assets/ uploads/dergiler/2014-2_ANA_METIN.pdf

[37] Fan L, Sidani S, Cooper-Brathwaite, A., Metcalfe, K. Improving foot self-care knowledge, self-efficacy, and behaviors in pilot patients with type 2 diabetes at low risk for foot ulceration: A Pilot Study. Clin Nurs Res 2013;23(6):1-17.

[38] Anastasi JK, Capili B, Chang M. HIV peripheral neuropathy and foot care management: A review of assessment and relevant guidelines 2013;113(12):34-40.

[39] Al-Gaows, FS, Al-Zahrani AM. Knowledge and practice of foot care among diabetic patients attending diabetic care center in Jeddah City. Int J Med Rev Case Rep 2019;3(11):664-670.

[40] Mohammed MAA, Rahman NAI. Knowledge, attitude, and practice of foot care among type 2 diabetic patients attending 
diabetic clinic Al Ribat Teaching Hospital in Sudanese patients. Advances in Diabetes and Metabolism 2018;6(3):34-53.

[41] Desalu OO, Salawu FK, Jimoh AK. Diabetic foot care: Self reported knowledge and practice among patients attending three tertiary hospital in Nigeria. Ghana Med J 2011;45(2):6065.

[42] Batkın D, Cetinkaya F. The Knowledge, attitude and behaviours of the diabetic patients on diabetic foot and foot care. Journal of Health Sciences 2005; 14(1):6-12.

[43] Corbett CF. A Randomized pilot study of improving foot care in home health patients with diabetes. Diabetes Educ 2003;29(2):273-282.

[44] Sriram M, Doke P, Dasila P. Effectiveness of foot care education among people with Diabetes Mellitus in urban community, Mumbai. Int J Pharm Biol Sci 2018;13(2):1-4.

[45] Barth R, Campbell LV, Allen S, et al. Intensive education improves knowledge, compliance, and foot problems in type 2 diabetes. Diab Med 1991;8(2):111-117.

[46] Bloomgarden ZT, Karmally W, Metzger MJ. Randomized, controlled trial of diabetic patient education: improved knowledge without improved metabolic status. Diab Care. 1987;10(3):263-272.

[47] Retting BA, Shrauger DG, Recker RR. Randomized study of the effects of a home diabetes education program. Diab Care 1986;9(2):173-179.

[48] Kruger S, Guthrie D. Foot care: knowledge retention and selfcare practices. Diabetes Educ 1992;18(6):487-490.

[49] Hamalainen H, Rönnemaa T, Toikka T. Long-term effects of one year of Intensified podiatric activities on foot-care knowledge and self-care habits in patients with diabetes. Diabetes Educator 1998;24(1):734-740.

[50] Rönnemaa T, Hamalainen H, Toikka T, Liukkonen I. Evaluation of the impact of podiatrist care in the primary prevention of foot problems in diabetic subjects. Diab Care 1997;20(12):18331837.

[51] Bains SS, Egede LE. Associations between health literacy, diabetes knowledge, self-care behaviors, and glycemic control in a low income population with type 2 diabetes. Diabetes Technol Ther 2011;13(3):335-341.
[52] Finfgeld DL, Wongvatunya S, Conn VS. Health belief model and reversal theory: A comparative analysis, JAN 2003;43(3):288297.

[53] Skinner TC, Hampson SE. Personal models of diabetes in relation to self care, well being, and glycemic control. Diab Care 2001;24(5):828-833.

[54] Kaymaz Kocak, D, Olgun N. To Be Acquired of Foot Caring Skill to The Type 2 Diabetics, Journal of Nursing Forum in Diabetes, Obesity and Hypertension 2009;1(1):28-37. Available from: http://www.tdhd.org/assets/uploads/dergiler/Dergi2009_1. pdf

[55] Litzelman DK, Slemenda CW, Langefeld CD. Reduction of Lower Extremity Clinical Abnormalities in Patients. Annals of Internal Medicine 1993;119(1):36-41.

[56] Saurabh S, Sarkar S, Selvaraj K. Effectiveness of foot care education among people with type 2 diabetes in rural Puducherry, India. IJEM 2015;18(1):106-110.

[57] Pieber TR, Holler A, Siebenhofer A. Evaluation of a structured teaching and treatment programme for type 2 diabetes in general practice in a rural area of Austria. Diabet Med 1995;12(4):349-354.

[58] Castro-Sánchez AM, Moreno-Lorenzo C, Matarán-Peñarrocha GA, Feriche-Fernández-Castanys B, Sánchez Labraca N, Sánchez Joya Mdel M. Efficacy of a massage and exercise programme on the ankle-brachial index and blood pressure in patients with diabetes mellitus type 2 and peripheral arterial disease: a randomized clinical trial.Med Clin (Barc) 2010;134(3):107-110.

[59] Castro-Sanchez AM, Moreno-Lorenzo C, Mataran Peñarrocha GA, Feriche-Fernández-Castanys B, GranadosGámez G, Quesada-Rubio J., M. Connective tissue reflex massage for type 2 dabetic patients with peripheral disease: Randomized controlled trial, Original Article, Evidence-Based Complemantary and Alternative Medicine 2011:1-12.

[60] Castro-Sanchez AM Mataran-Penarrochan GA, FericheFernandez-Castany BA. Program of 3 Physical therapy modalities Improves peripheral arterial disease in diabetes type 2 patients a randomized controlled trial. J Cardiovasc Nurs. 2013;28(1):74-82. 